Marek Sancho Höhne

\title{
11 Negotiating Gender in Germany-Normalizing Trans*Imaginations. On Aspects of Belonging to and Resisting the Normative Binary Gender Order
}

Knowledge about someone's gender seems to be of central importance in classifying them. Gender in Germany is-as in many other places-registered in identity documents, birth certificates and/or is coded in an individual's social security number. Also in everyday encounters, people seem to have knowledge about how to classify people according to gender. I am not always able to guess one's gender, but I am surprised that most of the people assume to know the gender of people, and most of the time I do not know when, and do not understand how and based on what markers, people gender-classify me. Depending on my own behaviour, the way I dress, and the people with whom I move around, I am sometimes seen as female, sometimes as male and most of the time as confusing. There seems to be a discrepancy in knowledge between me and my observers, concerning questions of what is visible and how we are able to understand and classify what we see.

Since visibility has in modern times become an imperative-what is "seen" is what is believed, or what is acknowledged to be real and thus can be recognized (Schaffer, 2008, p. 13)-gendered realities are also believed to be real if they are visible, or if they are approved as real and thus can be seen and acknowledged in the normative binary gender order. What is implicit in this assumption is that visibility is not something that simply exists "but is always produced in the relation between knowledge and power and is in mutual proportion to invisibility"198 (Schaffer, 2008, p. 13). Genders which are visible and thus are recognized do not denote a stable system but are rather embedded in the net of knowledge and power around gender. That the body is perceived as an important informant about one's gender in the "culture of dominance" (Rommelspacher, 1998) in Germany is part of this net of knowledge and power (Höhne, 2017, p. 25). This net is deeply embedded in questions of temporality and locality. Therefore, I do not argue simply for the greater visibility of trans ${ }^{\star}$ people in my paper, but rather for the need to question the possibilities of visibility and recognition of (different) genders (Schaffer, 2008, pp. 18-19).

In this chapter I will examine some features of mapping gender and belonging from the perspective of a culture of dominance by analysing some narrations about and by trans` people. How can we observe the negotiation of gender in the

198 This translation and the following translations show the original citation in German: "sondern immer in einem Zusammenhang aus Wissen und Macht produziert ist und in einem gegenseitigen Modulationsverhältnis zu Unsichtbarkeit steht” (Schaffer, 2008, p. 13). 
imaginations of trans ${ }^{\star}$ individuals within the framework of a culture of dominance? In particular, I wish to question the ways that trans ${ }^{\star}$ people are imagined and rooted in ongoing German public discourse (e.g. in mainstream media) and medico-legal knowledge and how trans ${ }^{\star}$ lives are recognized in this setting: Are they seen and/or recognized and, if so, how and under what conditions? How does what Schaffer calls the "dehumanizing violence" by "non-status of the unreadable"199 (Schaffer, 2008, p. 20) affect the lives of individuals who identify as trans`? How does stereotypical and pathologizing intelligibility form possibilities for trans`ness within a culture of gendered dominance? Conversely, if trans ${ }^{\star}$ people are only recognized in a pathologized intelligible form, it is still a form of visibility and does it thus gain political power in the frame of the culture of dominance (Schaffer, 2008, pp. 20-21)? How does this affect the lives of trans` people? I argue that by identifying certain trans ${ }^{\star}$ bodies as the only intelligible ones, which can enter into the normative binary gender-order, a process is thus initiated of normalizing certain imaginations of trans bodies. This signifies not only a negotiation of the boundaries of the binary gender order, but also the negotiation, taken in a broader sense, of belonging and the classification of "us" and "them". Furthermore, I will inquire into how simplification and attempts of separating intersectional, i.e. gendered, class-determined, and racialized realities (among others) fail to grasp trans* lives. This article hence also aims to illustrate how imaginations of trans ${ }^{\star}$ are connected to questions of (national) belonging.

I comprehend the different imaginations of passing trans ${ }^{\star}$ bodies into the normative binary gender order as negotiating precarious bodies and thus precarious lives (Butler, 2010, pp. 2-3). It is thus the negotiations of an individual's life that is produced according to certain deep-seated norms, through which we can observe how these norms of apprehending and recognizing a life are at stake while imagining trans identities. Imagining trans bodies that can pass in terms of the binary gender order I understand here as a b/ordering process of gendered normality at the intersection of gender with "race," ability, age, class, religion and ethnicity, and as thus entangled in the question of which "lives ... are not quite-or indeed, are never-recognized as lives” (Butler, 2010, p. 4). What life is to be recognized as a life? What body is to be constructed as a precarious body-a body whose life is always in danger of being denied? Moreover, how is the negotiation of trans entangled with negotiations of precarious bodies at its intersection with other power structures? Trans ${ }^{\star}$ realities are thus always part of negotiating the normative framework of the dominant binary gender-order and the circumstances through which bodies become recognizable or (more) precarious.

In my chapter I will first illustrate how trans* bodies are framed in the medicolegal system (section “Trans^ Bodies From a Medico-Legal Perspective”). After this, I will analyse by means of two different examples-an attack against trans` women

199 “entmenschlichende Gewalt” durch “Nicht-Status der Unlesbarkeit” (Schaffer, 2008, p. 20). 
(section "First Insight: On the Racialization of Trans* Discriminatory Violence”), and the election of a trans* officer to the federal armed forces (section "Second Insight: Trans` People and the Army-Trans* Nationalism at Work")-how, with respect to trans lives, questions of gender and national belonging are discussed in Germany. I argue that the discussions do not actually care about the trans lives they are supposedly dealing with, but that they rather function as wildcards that argue for an assumed progressiveness of dominant society in Germany and thereby strengthen the distinction of the dominant society from the racialized other. In the last part of the article (section “Trans* Life Stories-Self Narrations as Resistance”), I show how both medico-legal knowledge and the instrumentalization of trans ${ }^{\star}$ themes in public discourse fail to grasp the challenges that concern the lives of trans people, by sharing some extracts of my ethnographic fieldwork on trans` lives in contemporary Germany.

\subsection{Trans* Bodies From a Medico-Legal Perspective}

Binary gendered attributions, as I argued above, are of importance for different aspects of life-worlds. Gender-in all its intersectional dimensions-is an important signifier in order to classify people. The culture of dominance in Germany is based on binary gendered norms that imply intersectional normative imaginations of the female and the male. Michel Foucault outlined how psychiatrists of the $19^{\text {th }}$ century introduced "[t]he medicalization of the sexually peculiar" (Foucault, 1978, p. 44) and how the pathologization of diverse sexualities that diverge from the heterosexual, monogamous, reproductive couple was developed. By this dichotomy between girls and boys, the production of the "real sex" was manifested and sexual practices were regulated. The growing control of sexuality and the production of distance between, and shame towards, the female and male have exacted an enormous influence over the current normative binary gender order (Foucault, 1978, p. 46). Judith Butler (1991) similarly argues that the limits of the normative binary gender order also marks the boundaries of those genders which are acknowledged as "real," truthful, or authentic-or as Butler says-intelligible, and thus the imaginations of which "normal bodies" can pass (p. 38). Gendered bodies and/or identifications that differ from the normative imagination are in this pathologized system other-ed and labelled. Trans ${ }^{\star}$ bodies are just one of them.

Using the term "trans ${ }^{\star}$ " is already complicated, being embedded in medical classification and connected to colonial knowledge, since gendered practices of the normative binary are part of colonial knowledge (Aizura et al. 2014, p. 311). In colonial knowledge the assumption of a binary gender is naturalized and blended into the so-called modern sciences, as discussed by Lugones (2008, p. 84). In this context medico-legal knowledge becomes an important part of the modern sciences, since it reflects in a more detailed way on the question of gendered passing. As I (Höhne, 2017) have contended elsewhere, "ultimately medico-biological, violent dominant 
knowledge produces the truth, on which basis it is decided, which bodies fulfill the normalized categories and which don't”200 (p. 33). Trans ${ }^{\star}$-specific healthcare and the narrative of the "wrong body" that can be adjusted to the dominant imaginations of female and male is firmly embedded in the modern sciences. In this sense, as Thamar Klein and I (Höhne \& Klein, 2019) have argued elsewhere, "it is important to question the alleged connection between trans* narratives of becoming and the naturalized assumption of the need for medical and surgical intervention to adjust the supposedly wrong body" (p. 10).

Medico-legal knowledge about trans* bodies is dominated by the (psycho)pathologization of trans` people. Transsexuality is listed in the "International Classification of Diseases" (ICD) in the chapter on "Classifications of Mental and Behavioural Disorder: Clinical Descriptions and Diagnostic Guidelines," the current ICD-10 201 as "gender identity disorders" 202 under the classification F64.0 and is defined as a cross-gender identification that is perceived as something curable, if the person can prove that they are suffering from it sufficiently (World Health Organization [WHO], 2016). This categorization differentiates between the "true transsexual" who suffers persistently and significantly owing to their gender assigned by birth and strives to change parts of their body with hormonal treatment and surgery, in order to be recognized-in normatively binary gendered orders-as the "opposite" gender and diagnosed with F64.0 and other gender-variant people (F64.1-9). The latter diagnosis does not allow people to obtain access to any gender reassignment procedure. In the classification of F64.0 the process, which is also described as transition, is connected to the idea of a journey and thus to the question of temporality and spatiality. Transition is understood, on the one hand, as a liminal time-frame at which end stands an assumed progress and arrival, whereupon the person arrives at their "desired gender"

200 'weil letzten Endes das medizinisch-biologische, gewaltvoll dominante Wissen die 'Wahrheit' produziert, auf deren Grundlage darüber bestimmt wird, welche Körper den normierten Kategorien entsprechen und welche nicht” (Höhne, 2017, p. 33).

201 I refer to the ICD-10, even though the ICD-11 was adopted in May 2019. However, the ICD-10 will be still valid in Germany until 2022 and therefore will still structure the procedure in Germany for at least some more years.

202 I also refer here to a quote from another paper, which Thamar Klein and me (Höhne \& Klein, 2019) wrote as it applies for this article in the same way: "While working on this paper, it has been announced that all trans*-related categories will be deleted from the ICD Chapter on Mental and Behavioural Disorders in the future ICD 11 (pending approval by the World Health Assembly in 2019) as a result of the tremendous effort by trans ${ }^{\star}$ activists from around the world. Instead, the new categories, 'Gender Incongruence of Adolescence and Adulthood' and 'Gender Incongruence of Childhood' have been placed in a new chapter, provisionally named 'Conditions Related to Sexual Health.' Thus, being trans ${ }^{\star}$ will no longer be regarded as an implication of a mental disorder. However, there is still a lot of work to be done, as othering and normative language has been preserved, and the dangerous GIC category aimed at eradicating gender diversity in childhood needs to be removed (for a more detailed critique, see [Asia Pacific Transgender Network] APTN 2017)” (p. 25). 
in full (read: in a bodily sense). On the other hand, this phase is imagined as a space between female and male (Aizura, 2018, p. 2). Aren Aizura (2018) further argues that "[p]opular ideas about gender reassignment reflect the assumption that transness is the same for most people (we often assume that trans people desire hormones or surgery, for example)” (p. 3). On this understanding, all trans ${ }^{\star}$ people pass once through the liminal phase of transition, a phase where they move from the gender to which they were assigned by birth to the supposedly opposite one, which is made possible by modern medicine that offers gender reassignment treatment and surgery. Aizura (2018, p. 3) here argues

that transsexuality, the normative Euro-American category of trans subjectivity, becomes intelligible as a modern concept through its staging as a journey through "elsewhere" spaces: spaces in which it is necessary, momentarily, to inhabit a gendered indeterminacy that is intolerable under the law of heteronormative binary gender but also necessary for narrating the seeming impossibility of gendered transformation.

This understanding does not just perpetuate the imperially-minded behaviour that assumes Euro-American colonial imaginations which are applicable to the whole world, but also makes any existence of trans ${ }^{\star}$, inter ${ }^{\star}$, non-binary, two-spirit or other gender-specific understandings beyond the normative binary impossible.

In Germany the Medizinischer Dienst des Spitzenverbandes Bund der Krankenkasse e.V. (MDS, 2009) [Medical Advisory Service of the German Social Health Insurance] publishes the "Begutachtungsanleitung Geschlechtsangleichender Maßnahmen bei Transsexualität” [guidelines for the examinations for gender reassignment treatment in case of Transsexuality]. In these guidelines trans* identities are treated-under the term Transsexuality-as a treatable condition that is classified and approved by healthcare professionals. These guidelines say that a medical authority needs to determine who and under what circumstances an individual is allowed access to hormonal treatment or surgeries. A person needs to undergo psychotherapy, a so-called "Alltagstest" [full-time real-life experience], according to which a person needs to live in the "opposite gender" and has "to be out" in the public and private sphere for one full year (MDS, 2009, p. 10). Co-morbidity should be precluded and one has to prove a "krankheitswertiger Leidensdruck" [pathologically significant degree of suffering] (MDS, 2009, p. 10). The guidelines justify the socio-medical assessment by the supposed complexity of the "disorder" that demands qualified experts. Their counseling and assessment serves-following these guidelines-as a protection of the insured person, in order to prevent "wrong-positive diagnosis" (MDS, 2009, p. 6). Neither are trans* people themselves considered experts nor is the assumed necessity of treatment-in the case that the "experts" diagnoses the person with F 64.0questioned. Striking is also the significance of "normalization" in this context, that seems to be therapists' answer to pathologization (Nieder et al., 2012, p. 7). After the diagnosis has been given and the "suffering" has been acknowledged, therapists and doctors do their best in "normalizing" the life of the person, especially with regard to 
overcoming the ambiguity and mitigating the suffering of gender dysphoria. Just to make this point clear, suffering here is not meant as a suffering of the heteronormative binary gender order, but of one's individual (gendered) body. "Normalization" in this context is directly linked to the idea of making a person fit into the normative gender binary. I do not intend to convey any negative judgment about the individual decision of a person who chooses gender reassignment surgeries or hormonal treatment, as I myself have undergone hormonal treatment and body modifications in order to adjust my body to my own gender. Having access to gender reassignment surgeries or hormonal treatment (often people make use of only some of the available possibilities) can be, for some people, the access to survival and healing.

Problematic is the unquestioned link between medical treatment and trans* bodies. The dysphoria that may exist between one's own understanding of one's gender and possible gender identifications in the culture of dominance is treated as an individual problem that can be cured by medical treatment. This may be true in many cases, as it enables the recognition of a certain gender which one belongs to against the classification of a gender made by birth. However, this implies that being acknowledged as a trans` person (reads: true "transsexual” according to medical classification) in the culture of dominance requires access to the healthcare system. Further access to the German healthcare system requires a certain national belonging either by passport, residence status or by being granted permission to work there. All this already sets the condition for (national) belonging to those people that are entitled to have rights (Arendt, 2006, p. 614) and that have not been "illegalized" or are not forced into the abeyance of the "refugee status." Those whom Hannah Arendt (2016) names as suffering, especially from a fundamental lack of rights and who cannot claim their access because of having lost the right to have rights (p. 613), cannot even gain access to being acknowledged through the precarious status of pathologization. Moreover, the criteria of the healthcare system assumes able-bodied individuals, with the result that those bodies which are classified as "disabled," "mentally ill" or pathologized by a diagnosis such as "learning disabilities" are less frequently allowed access to trans* specific health care or are asked to perform further tests concerning their ability to make decisions about their own lives and bodies.

Knowledge of the normative binary gender order is more explicitly expected of gender-variant people and engages in very intimate spheres of their lives, and not just with respect to medico-knowledge. There is another aspect of trans ${ }^{\star}$ gender that seems to be highly important when looking at constructions of normatively binary gendered knowledge. To maintain the dominant knowledge (production), it is necessary to secure the legal aspects of gender markers in order to prevent the disturbance of the system itself. In Germany, gender is still registered in all legal documents, either by name, gender marker or number (e.g. for pension insurance). In order to change one's gender as registered in one's birth certificate and/or documentation as a trans ${ }^{\star}$ person, one needs to undergo a process which conforms with the "Transsexuellengesetz" [transsexual act] and be approved by two psychiatric/psychotherapist 
“experts," namely a diagnosis of F 64.0, after which a court makes a final decision about the change. However, if one changes one's gender marker from female to male and later gives birth (as lately confirmed by Bundesgerichtshof [Federal Constitutional Court]), the person needs to be registered as a mother with their name given by birth instead of being registered with their current gender marker and name. ${ }^{203}$

Both the medical and the legal complexities of this issue demand and reproduce a narrative of a linear development, where trans ${ }^{\star}$ people can be cured or saved by following a certain path of a logic of "from-to," which represents a journey through the liminal space and time, as discussed earlier. The problem of this path is its fixation on a linear movement, which fails to acknowledge the different decisions and life stories of trans ${ }^{\star}$ and other gender-variant people. On this logic there are persons who are denied access to treatment through the perception and classification of not being "trans* enough." What happens with trans* or other gender-variant people who resist or do not comply with the medico-legal knowledge? Do those resisting practices help to blur the boundaries of the normatively binary gender order, or do they unintentionally participate in strengthening them? And who is actually heard when reformulating classifications of trans` ${ }^{\star}$ ender in Germany? What happens if medicolegal systems are changed almost entirely without the participation of gender-variant people? These questions cannot be answered thoroughly in all their aspects here. In this article, nevertheless, I raise these questions, as they are of great importance for the understanding of the different realities of trans* lives and they need to be discussed further.

\subsection{Trans* People in Media Between Instrumentalization and Misrepre- sentation-Two Insights}

A lot of media coverage in German popular newspapers and TV formats concerning trans` lives (see e.g., Reporter, 2018) focuses on medico-legal aspects of being trans*.

203 In November 2017 the Federal Constitutional Court ruled about the question of registering Gender in official documents. The court gave two options: an abolition of gender markers in documents and birth certificates, or at least the introduction of a 3rd Gender-besides female and male-such as "diverse" or "inter»/ other”. In November 2018 the Ministry for Internal Affairs published a draft law for a third positive gender marker "diverse". Instead of opening up the third positive gender marker for everybody without medical diagnosis, the third positive gender marker is linked to a medical certificate that proves the variance of sex-development ["Variante der Geschlechtsentwicklung"]. This new law neither pays tribute to the claims of inter ${ }^{\star}$ activists who demand a guarantee for no more unwilling surgeries on intersex children and access to a change of the gender marker without any medical certification, nor does it include the variety of trans ${ }^{\star}$ and non-binary people. The new regulation still demands a medical certificate and does not guarantee the prohibition of unwilling surgeries for inter* people. 
This is presented as the real (read: scientific) dominant knowledge about trans* people, without, however, being presented by non-trans* people for other non-trans* people in order to prepare the dominant society for the gendered "Other”. Trans* people are presented as a "Laune der Natur" [freak of nature], that seems to be different but is in fact part of the "norm_al," just in a different shape. As for the question of Othering processes, it is of interest that those reports, documentaries and articles that focus on the medico-legal complexities of trans* peoples issues are also the ones who allege to provide neutral reporting-as opposed to media that exoticize, fetishize or ridicule trans* people-and to present the "naked truth" about trans* people, by differentiating them from the norm_al and other "deviations" such as inter^ people. "Us" is linked not only to questions of belonging, national identity, and self-identification but also the way one is read by Others. This becomes evident in two very illustrative examples which I will present in the following chapter. I choose these two examples because they display a certain kind of assumed normality concerning trans ${ }^{\star}$ people in Germany, while negotiating who counts as a trans* person by association with the individual's national belonging. In both cases the articles and documentaries try to show how a form of inclusion of trans ${ }^{\star}$ people, as something that belongs to Germany, makes Germany a part of the progressive "Western" world. In these articles it also becomes clear how this works in very different ways and how, still in this context, it is negotiated which trans ${ }^{\star}$ people are trans ${ }^{\star}$ enough within this frame of time and space.

\subsubsection{First Insight: On the Racialization of Trans* Discriminatory Violence}

Shortly after the events in Cologne at New Year's Eve in 2016, two trans ${ }^{\star}$ women were attacked in Dortmund. On New Year's Eve a chaotic situation in and around the main train station in Cologne arises. A big crowd of young men gathers, at the bridge next to the train-station a mass panic sets in, and in and around the train station several women were sexually harassed. Shortly after this night, this very unclear situation becomes a projection surface in the political debate on refugees. In the end, a racist atmosphere against refugees remains. The media coverage about an attack in Dortmund draws a parallel with New Year' Eve in Cologne and thus refers to anti-refugee sentiments. Discrimination and violence against trans` people happen in Germany on a regular basis, but is not part of the wider media coverage. The attacks in January 2016 were covered especially by private television broadcasters (Noislamisation, 2016), conservative and anti-feminist media such as the KOPP publisher (e.g., Jung, 2016) or in Catholic news [Katholische Nachrichten], via an online German Catholic newsportal (e.g., Katholische Nachrichten, 2016), the protest media Telepolis (e.g., Mühlbauer, 2016) and in papers with a wide circulation such as BILD, a popular German yellow press newspaper (e.g., Wegener \& Engelberg, 2016), and Focus, a monthly popular political journal with an online format (e.g., Focus online 
regional, 2016). The story that is told is that the two "transsexuals" were first "verbally attacked in Arabic" and later suffered an attempt to stone them to death by three "North African men," but the two women were rescued by police who happened to be passing by (e.g. Noislamisation, 2016; Jung, 2016; Katholische Nachrichten, 2016; Mühlbauer, 2016; Wegener \& Engelberg, 2016; Focus online regional, 2016). This reads as something planned and makes sure that the attacks are identified as something extraordinary connected to the origin and/or religion, age, and gender (male) of the potential attackers. Some of these articles identify the three men through such racial profiling as "North Africans," and all declare the attack as a threat to liberal society. It is not surprising that-apart from yellow press such as Bild or Sat. 1-it is mostly conservative and antifeminist media such as the Catholic news [Katholische Nachrichten], an online German Catholic newspage, the internet platform heise.de, or the media service Telepolis that covered the incident, all media of which are not known for their trans ${ }^{\star}$-inclusiveness. On the contrary, all articles "other" the two women for being trans* women and reproduce highly trans*-discriminatory language, calling the two trans* women as "men, that dress as woman". Bild, for example, instead of writing about an attack against trans* woman, writes: "Because they were dressed in women's clothes two Transsexuals were stoned in Dortmund”204 (Wegener \& Engelberg, 2016). The Catholic News stated: “Three adolescents harassed the men that are living as women" 205 (Katholische Nachrichten, 2016). Focus feels the urge to clarify that the woman "who were born as men"206 (Focus online regional, 2016) escaped the attack without any injuries and Kopp publisher states that "shortly after the ... North African man realized that they were actually dealing with transsexual men"207 (Jung, 2016). In none of the articles or reports about the incident do the two women receive space to explain the situation in further detail. The internet platform heise. de, however, tries to give a more profound interpretation of the incident. They try to use female pronouns for the two trans* women and show that one of the attacked women also spoke Arabic. By giving a more detailed short history of stoning (which was focused on an Islamic context, but which also mentioned stoning in ancient Christian and Greek contexts), the report later connects this one incident to several others where people with a precarious legal status or racialized others are classified as perpetrators. The image of stoning somebody to death is in the German culture of dominance connected to a death penalty, which is practised mostly in contexts where Sharia is the basis for law. This is explained more explicitly in the article at the online

204 "Weil sie in Frauenkleidern unterwegs waren, sind zwei Transsexuelle in Dortmund gesteinigt wurden” (Wegener \& Engelberg, 2016).

205 “Drei Jugendliche bedrängten Männer, die wie Frauen leben” (Katholische Nachrichten, 2016).

206 “die als Männer geboren wurden” (Focus online regional, 2016).

207 "Doch kaum hatten die ... Nordafrikaner erkannt, dass sie es mit transsexuellen Männern zu tun hatten” (Jung, 2016). 
German Catholic news portal (Katholische Nachrichten, 2016), who refer to the press release of the media service Telepolis, who write: "According to the information of the media service Telepolis ... stoning to death is provided for a penalty for fornication in different Islamic countries such as Saudi-Arabia, United Arab Emirates, Brunei, Pakistan, Sudan, Iran and Northern Nigeria"208 (Katholische Nachrichten, 2016).

Problematic is also the way that what is written about is not the condemnation of stoning or more generally the violence against trans ${ }^{\star}$ people, but that:

1. It is written just about this specific case, instead of writing in general about violence against trans ${ }^{\star}$ people, a case where the attackers are racialized.

2. By the wording of the attempt of stoning the two trans* women to death and the direct connection to Muslim countries per se, trans ${ }^{\star}$ discriminatory violence is racialized, while the victims are de-racialized. This suggests that, in the culture of dominance in Germany, trans* discriminatory violence does not happen (which is not true at all, as we can observe in the trans ${ }^{\star}$ discriminatory vocabulary of the articles for example).

3. Temporality is introduced by labelling "the others"-the attackers-as backward (because of their coming from North African ["Muslim"] countries, and producing an image of "us" as the progressive German dominant society. In this discourse the supposed trans*-inclusion is labeled as modern (read: "Western").

4. By racializing trans ${ }^{\star}$-discriminatory violence the existence of trans* people of colour and Black trans* people is denied and the complex realities of trans ${ }^{\star}$ people and the actual violence and discrimination against trans ${ }^{\star}$ people, especially against trans ${ }^{\star}$ people of colour and Black trans* people, is silenced.

5. The violence and discrimination are classified into illegitimate (physical attack) and legitimate (structural discrimination, rejection of one's identity) forms of violence, by the wording in these different reports, in which structural violence and discriminatory language against trans ${ }^{\star}$ people is reproduced, while the physical attack is condemned.

All these processes and classifications that can be observed in the analysis of these articles are not new. Rather, they are connected to a complex power system along lines of "race," gender, class, age, and ability (among others) in a culture of dominance, which is spelled out in different ways in various spheres within which mass media discourses play an important role. In this complex power system (gender) identities are racialized by the supposed association of "gay- and trans*-friendliness" and non-sexism with white Germans, in opposition to homo-, trans ${ }^{\star}$ - and sexist discrimination, which is allegedly associated with traditional and non-white Germans. These

208 "Nach Angaben des Mediendienstes Telepolis (Haar bei München) sehen mehrere islamische Länder die Steinigung als Strafe für Unzucht vor, beispielsweise in Saudi-Arabien, Vereinigte Arabische Emiraten, Brunei, Pakistan, Sudan, Iran, und Nordnigeria” (Katholische Nachrichten, 2016). 
discourses are connected to the image of "homophobic Islam," and label imagined "Muslim communities" as "misogynist and brutal” (Çetin \& Prasad, 2015, p. 108). In this context, white dominant society determines discourses about the acceptably sexualized, gendered, class-related, able-bodied and racialized subject. Acts of violence and hatred directed against trans ${ }^{\star}$ people are often imagined as springing from communities of colour (Haritaworn, 2012, p. 12). However, they also generate the new German core value of "women-and-gay" (and lately also "trans *”) "friendliness" (Haritaworn, 2012, p. 14), that prevents narratives and embodiments beyond the dominant binary gendered discourses.

\subsubsection{Second Insight: Trans* People and the Army-Trans*-Nationalism at Work}

Another article was published almost one year later. This time a picture of a young Federal Armed Forces Officer is presented on the cover page of Berliner Kurier (a yellow local press newspaper) with the headline: "Lieutenant-colonel Anastasia from Berlin and her story, which gives courage. Ms. Officer was once a Man" ${ }^{209}$ (Oberstleutnant Anastasia aus Berlin und ihre Geschichte, die Mut macht, 2017, p. 1). She looks straight into the camera and wears a chin-long blond layered modern haircut, has blue eyes and wears small studded earrings. Indeed, if she were being painted and not wearing a uniform, she could be the cover face for any article that focuses on middle-class women in Germany. In the short picture-descriptions (Ortmann, 2017, p. 29) the acceptance of the military towards trans* officers is celebrated. It is written that one day she decides to get her ears pierced-which is forbidden for men in the Federal Armed Forces-and that she has come out after 20 years of a double-life that gave her suffering, where she lived the life of a male officer at work and wore women clothing and a wig in the evening. "At work I tried to show off the man, I wanted to make a career and not confront myself all the time with my transsexuality"210 (Ortmann, 2017, p. 29). She confesses-to put it in Foucauldian terms-that she suffered, reaffirming dominant imaginations in medico-legal knowledge of trans ${ }^{\star}$ gender, as described above, but also addressing the issue of the need to first make a career and just later being able to present herself at work. In the article, it is also described how step-by-step she reveals herself to different people at work and in private space, and the great acceptance she receives is emphasized. "Nobody abandoned me, I was supported at all levels. I am grateful for this"211 (Ortmann, 2017, p. 29). It is written further that her wish to live

209 "Oberstleutnant Anastasia aus Berlin und ihre Geschichte, die Mut macht. Frau Offizier war mal ein Mann” (Oberstleutnant Anastasia aus Berlin und ihre Geschichte, die Mut macht, 2017, p. 1).

210 "Ich habe versucht im Dienst den Mann hervorzuheben, wollte Karriere machen und mich nicht ständig mit meiner Transsexualität auseinandersetzen” (Ortmann, 2017, p. 29).

211 "Niemand hat sich abgewandt, ich hatte Unterstützung auf allen Ebenen. Dafür bin ich dank- 
as a woman becomes stronger and that she was mentally in poor health, which is explained by the common narrative of "being trapped in the wrong body". Her coming-out as a trans ${ }^{\star}$ woman to her superiors is described as just one step in the path as a "Transsexual," as it is put in the article. Ortmann (2017) describes further: "But there is still a lot to be done. Therapeutic accompaniment, psychological testing, medical opinions, hormonal treatment, undergoing the every-day real-life experience.” (p. 29) One important step she has already managed: the gender marker. The gender here named is officially changed in her new documents-even in the forces documents. At the end Anastasia is quoted: "Finally I am [a] woman-also in the Federal Armed Forces”212 (Ortmann, 2017, p. 29). At the side of the article a small information box is placed under the title „Sex-Seminar at the Federal Armed Forces” (Ortmann, 2017, p. 29). The related seminar "Dealing with sexual Identity and Orientation" is part of the programme of the Ministry of Defence for welcoming diversity in the Federal Armed Forces. This article is not part of a serial of portraits of trans ${ }^{\star}$ people, nor is the issue of this specific day dedicated to gender or diversity and the newspaper is not known for its trans ${ }^{\star}$ respectful reporting.

The violence inherent in the described procedures or the discrimination she faces, for example by being addressed in the article as formerly being a man or by the prejudices she is confronted with, is not given. Neither does the article give any idea about her life and her personality. It is not the person Anastasia that is of interest here. It is the portrayed officer that fulfils stereotypical images of being Germanblond, blue-eyed, white, able-bodied, serving the state-but particularly for the national body, which is represented here by the military itself. The article reads as if it would be a manual of how and under what circumstances a trans ${ }^{\star}$ person can gain access to belong to the national body, and as if it intends to prove the inclusiveness of the military by asserting that even (gender and sexual) minorities are (now) allowed access to this professional sector. Despite following the path of the medicolegal system, being German entails access to the military that completes the belonging. The figure of the portrayed officer is in this context pictured as a perfect (German) female person and thus as a certain norm of a trans ${ }^{\star}$ person who can gain access to the national body. By presenting the imagination of Anastasia and showing that even the Federal Armed Forces accepts trans` people, trans ${ }^{\star}$ people in the military become part of the imagined community of "us" (the German national body), while all violence against trans* people is silenced and thus all the ambiguities that are part of trans ${ }^{\star}$ realities in Germany are blanked out, even though they are also part of the article itself (such as calling Anastasia a former man). Here, we can observe a mechanism of trans ${ }^{\star}$-nationalism ${ }^{213}$ in power, which is derived and borrowed from

bar” (Ortmann, 2017, p. 29).

212 "Ich bin endlich eine Frau-auch bei der Bundeswehr" (Ortmann, 2017, p. 29).

213 I use the term trans*-nationalism as Jasbir Puar (2007) uses the concept of Homonationalism- 
Puar's concept of Homonationalism (Puar, 2007). Homonationalism explains how the demands for gay and queer equality “are taken as an indicator of 'progress' in modern, Westernized societies, which at the same time racializes homophobia and risks perpetuating white-Western supremacy," a point that I have illustrated previously in an article with Dmitri Heerdegen (Heerdegen \& Höhne, 2018, p. 240). This concept can be understood as an

analytic to apprehend state formation and a structure of modernity: as an assemblage of geopolitical and historical forces, neoliberal interests in capitalist accumulation, both cultural and material, biopolitical state practices of population control, and affective investments in discourses of freedom, liberation and rights. (Puar, 2013, p. 337)

Homonationalism does not mean a substantial acceptance of homosexuality in Western societies, but rather a situational, instrumental and thus precarious use of Homosexuality as a wildcard. In this sense I translate the inclusion within homonationalism of trans ${ }^{\star}$-nationalism. There is not a substantial acceptance of trans ${ }^{\star}$ people in Germany, but the article rather illustrates an instrumentalization of trans ${ }^{\star}$ lives for political goals without existing trans ${ }^{\star}$-antidiscriminatory politics in the culture of dominance.

I argue that both cases analysed here are part of normalizing trans ${ }^{\star}$ representations as inherently German that proves German modernity and progress. Both are examples of a specific way of dealing and instrumentalizing trans* people in popular discourse. They are particular examples, since in both cases the trans* individual serves as a figure through which the connection of gender and belonging (to "us" or "them") in a German context is discussed. The life-worlds and experiences of trans* people do not lie at the centre of interest, but, on the contrary, trans* people are thereby instrumentalized to illustrate the understanding of belonging in the culture of dominance. All the contradictions inherent to these cases are hidden and the trans ${ }^{\star}$ discriminatory conditions under which trans ${ }^{\star}$ people survive the heteronormative binary gender order are blanked out. Even more starkly, in both cases such media coverage invokes trans ${ }^{\star}$ discriminatory topoi and reaffirms them.

\subsection{Trans* Life Stories-Self Narrations as Resistance}

The urge to change one's own body as a trans*person, as created in medico-legal knowledge, translates in popular as well as in scientific discourses into the suffering

which is explained later in this chapter-in order to describe the figuration of Western modern nationalism and Homosexuality. The term should not be confused with Steven Vertovec's (2009) concept of transnationalism. To make this clear I write trans*-nationalism. 
of the wrong body. Jay Prosser (1998) calls this narrative a "transsexual leitmotif" (p. 69), which is not simply imposed on trans ${ }^{\star}$ people, but which is rather "materialized as somatic feeling" in what transsexuality supposedly feels like (p. 70). Similarly, Josch Hoenes (2014) points to the ambivalence of the narrative of "being trapped in the wrong body," that may be an appropriate description of how some trans ${ }^{\star}$ people feel but is still a problematic normative view and limited in its description (pp. 102103). I would add that it reaffirms the normative binary gender system and thus limits trans ${ }^{\star}$ narratives and life stories. No person is to blame for making the decision to take hormones or undergo gender reassignment surgery. No (gender-variant) person who decides for this reaffirms the normative gender binary more than dyadic-cis people do. I want to emphasize that this dominant narration brings up what I mentioned above: the very complex contradiction between deconstructing and questioning the binary gender order and its normalizing power on gender variant people on the one hand, and the materialized somatic feeling of the urge to adjust parts of one's body along imaginations implemented by the normative binary gender order, on the other hand. And this dilemma is big. Similarly, the decision "to resist" and not to adjust one's body also still remains in the same logic. In the somatic translation of trans* imaginations we can observe the strength of the normative binary gender order. Even though I would argue that any trans* body, as with all other gender variant bodies, is still an important disturbance of the normative binary gender order. Moreover, it is one thing to question and deconstruct normative binary gender orders and another to try to find solutions to survive all the violence directed against non-normative binary gendered bodies (among them trans* bodies) within the heteronormative binary gender system.

\subsubsection{Healing and Reconciliation}

One of my dialogue-partners, Tabea-Sophie, discovered at an early age that she ${ }^{214}$ was somehow special. Tabea-Sophie describes having a searching perspective through all her life- a search for herself. This search however-once she realized her own womanhood-is not connected to the searching processes inscribed in dominant trans* narratives about how to make one's own body fit into a narrative of normatively binary gendered bodies. However, it is connected to the search for a place for her own existence in a normative order that was not expected of her. Her quest occurs in the search for the name that fits Tabea-Sophie's personality and her range of identifications. Tabea-Sophie is sure about not wanting to fulfil expectations and not wanting to adapt either herself as a person or her body to dominant imaginations.

214 Concerning pronouns I follow the wish of the respective person. 
Well, I am who I am, and it's somehow enough all the inner struggles and problems I have, I needed to adjust myself my whole life somehow and disguise, and I do not want to do that any longer, now that I found out or while I am finding out who I am. ${ }^{215}$ (Tabea-Sophie, personal communication, July 18, 2018)

Tabea-Sophie is highly concerned about the narratives that are offered about trans* issues-not just in media but also in activist contexts. She receives the documentation in television or on (autobiographical) books on trans`normativity, where she learns about the narrative of the wrong body and the medical adjustment or discriminatory procedure of changing documents after being approved by a court. However, she strongly feels that there has to be some other solution. She feels like, once she found herself, she does not want to reject herself and thus also parts of her body anymore. She wants reconciliation with herself and the opportunity to heal and love the body she has. She lacks spaces and imagination that help people to heal from the pressures of normativity of knowledge on gender, and criticizes that, even in trans ${ }^{\star}$ specific counselling, psychological support, and trans ${ }^{\star}$ support groups, she is always confronted with a focus on the medico-legal complex and on the need to change her body. Yet she wants to reach a conciliation with her body, about which she was told it was not what it should be throughout her whole life. And she is able to do so because of her belief which she separates from religion as an institution. She perceives the institution of religion as an element of the normatively binary gender order that did harm to her. Due to her faith, she accepts herself the way she is, and she believes she was made this way for some reason. She feels that following the medico-knowledge of changing her own body would harm her and would be against the perfection of herself by nature.

\subsubsection{Heterogeneity of Trans* Embodiments}

On the international day to end violence against sex workers in December 2016, a diverse group of people gathered in a neighbourhood project in the district where most of the trans* sex workers working on the street go to work. People attending the event differ in their age, origin, language, profession, gender, and in education. It feels like a meeting of different worlds-some queer and trans ${ }^{\star}$ activists from other quarters in Berlin mix with the sex workers from the neighbourhood. The sex workers from the neighbourhood all identify more or less as trans ${ }^{\star}$ people, but most of them would fail to be recognized of being trans` according to medico-legal knowledge as

215 "Also ich bin ich und das, das reicht irgendwie, was ich für innere Kämpfe und Probleme habe und eh, ich hab, musste mich mein Leben irgendwie anpassen und verstellen und das will ich jetzt nicht mehr wenn ich jetzt raus gefunden habe, oder dabei bin raus zu finden wer ich bin" (TabeaSophie, personal communication, July 18, 2018). 
well as in the dominant imagination of trans ${ }^{\star}$ people in Germany. Some of them are not 24/7 dressed as a woman, while others are; some of them switch names and when addressing each other they sometimes switch in gendering between female and male. Even though all of them identify as trans ${ }^{\star}$ sex workers the variety of this appearance is huge. Not all of them have access to the German health insurance system and just some of them decide for, or are interested in, taking hormones. Most of them migrated from Eastern-European countries to Germany and sex work was the option to earn money as an East-European migrant trans ${ }^{\star}$ person. Most of them do not have contact with trans ${ }^{\star}$ communities in Germany, as e.g. the survey of the peer-to-peer support structure and network trans ${ }^{\star}$ sexworks states (Transsexworks, n.d.).

In one instance Dunja enters the room wearing a black pullover and some jeans; her hair is cut medium-length. In everyday life she could pass for an intellectual guy, but in her self-perception she is no more or less a woman than later at night after dressing in a more female way and putting on make-up. After dressing up, just shortly before the event where she is asked to speak in public, she wears black stiletto boots, a short dark skirt and an elegant beige blouse with a scarf. She puts on some make-up and a blond wig. Even though I see the difference between her at the arrival and later speaking at stage, I cannot see any different gender than simply herself-Dunja. However, just an hour earlier, she would have been denied access to many women and/or women-lesbian-trans* only spaces, but not in this space during this day. Being in the room all together, it becomes obvious that the understanding of trans ${ }^{\star}$ ness differs deeply from dominant trans ${ }^{\star}$ discourses. All of them identify problems mostly because of the intersection of their profession, their migration, and the lack of opportunity to rent a flat (in some cases) which intersects with their being trans ${ }^{\star}$ sexworkers. However, they all work together on the same street and support each other (as long as they are able to in their current situation) based on their trans* identification and the intersection with their legal status, housing situation and profession.

Discourses of the culture of dominance on trans ${ }^{\star}$ people are rarely concerned with these individuals' precarious living conditions. They are more concentrated on treating trans ${ }^{\star}$ bodies themselves as precarious. In this frame of trans ${ }^{\star}$ activism, certain aspects of trans ${ }^{\star}$ lives are argued to be included into certain norms of recognition "to produce certain subjects as 'recognizable'” (Butler, 2010, p. 6). These norms concentrate on questions of depsychopathologization, self-informed consent for trans ${ }^{\star}$ specific health care, anti-discrimination legislation, and inclusion (Bundesvereinigung Trans*, 2018). However precarious the individual life may be, those that are in the frame of norms which are not recognizable are most likely found at the intersections of multiple power dimensions. The life-worlds of the trans ${ }^{\star}$ sex-workers are often not part of what is negotiated in dominant trans ${ }^{\star}$ activism, and aspects concerning trans ${ }^{\star}$ people that are negotiated by the trans ${ }^{\star}$ sex-workers sometimes differ quite a lot from those which are negotiated in established politics as well as in trans ${ }^{\star}$ activist spheres. 


\subsubsection{Invisible Gender}

Another important moment concerning the perception of gender in general and of trans` gender more specifically occurred when I first met one of my interview partners, Florian with his partner Maja. Florian was wearing a blue shirt and blue trousers; his hair was cut short, and he had a beard. Maja was wearing a pale shirt with flowers and a half-length black skirt. Her hair was a dark brown wig, and she covered her five o'clock shadow with make-up. In this encounter it becomes obvious how gender is perceived, and so too trans* imaginations in the culture of dominance are based on visual aspects. Florian is blind and just heard my voice and knew that I am a trans* person with a name he reads as male. During this first encounter I was wearing makeup, big earrings, black trousers and a black summer blouse. Maja, a trans ${ }^{\star}$ woman that in the gaze of the culture of dominance sometimes had difficulties to pass as a female, asked me during our conversation "what I am”. She wanted to know if I am a trans* woman or a trans ${ }^{\star}$ man or something in-between. She was even correcting Florian by using male pronouns addressing me, and instead used female pronouns. Florian was very embarrassed by this situation and said that one does not ask this question to trans ${ }^{\star}$ people, and she should know about the difficulty of the situation when people question your gender, as her womanhood was often questioned in public. In this situation I did not understand what actually was at stake. Later I realized that I forgot to pay attention to the difference of how both of them are gendering people. While the partner gendered myself, based on the supposed contradiction of my deep voice and my visual performance, visual aspects of gender were not accessible to Florian. The partner was confused, as I did not comply sufficiently with her visual expectations of trans ${ }^{\star}$ maleness or trans ${ }^{\star}$ femaleness. My deep voice and facial hair contradicted her expectations that a trans* woman would reach to dismiss any male associated aspects. My outfit instead contradicted her expectation of trans*maleness, as she categorized my clothes, make-up and jewellery to be female. In our second encounter I described to Florian what I was wearing and asked him if he wants to see me with his hands. He touched my hair, that was longer than he expected, and realized that I did not have a beard. I gave him my jewellery which I was wearing and suddenly the question of his partner made sense to him, because he could relate to the confusion of my deeper voice, my body, which both of them describe as male with a sportive back, and all the things I was wearing. These he could not see during our first encounter as I did not invite him to see me in a manner accessible to him. Both of them challenge and are challenged in their everyday life by the normatively binary gender order, yet they-as any other person-also reproduce the expectations of the order itself and are thus challenged if I do not fulfil their assumptions on how trans ${ }^{\star}$ individuals can survive in the assumptions of the culture of dominance concerning the binary gender order. I do not want to question their gendered self-perception or their strategies to survive the expectations of the normative binary gender order in the culture of dominance. Rather, I understand this brief side-comment as another important aspect of 
mapping the landscape of the normative binary gender order and imaginations of trans ${ }^{\star}$ lifes, that needs to be analysed further. What I observe in these encounters are of importance for questions of visibility and how different access to what is visible to whom stabilizes or destabilizes the normative binary gender order.

\subsubsection{About Resistance and Adoption}

Despite the negotiations of normative binary gender in the culture of dominance, trans` people do not simply adopt, accept or realize the conditions of the normative binary gender order. Rather, in life story narrations of trans ${ }^{\star}$ people, the complex mingling of normalizing narrations and the complexity and variety of gender in general, and of trans ${ }^{\star}$ gender specifically, becomes recognizable and accountable. It is not a one-way-street where the normative gender order narratives translate one-toone into life stories of people of different genders, but rather an interaction and negotiation between different actors, aspects, narrations, and views. It is the interaction that spawns the different specific ways of trans ${ }^{\star}$ formations. These negotiations and impossibilities of belonging and gender can be observed specifically in the life stories of trans ${ }^{\star}$ people, as they are particularly often openly forced to navigate through the conditions spelled out in the dominant normative binary gender order. Furthermore, we can observe that trans* people are not passive victims but are engaged in the culture of dominance of the normative binary gender orders and adjust, influence and change dominant narrations. Zowie Davy argues in this context how:

Transsexuals acknowledge that the medical discourses that are interpreted by the doctors and psychiatrists require perceptive manipulation. Thus, transsexuals' own discourses have both agentic and subjugating elements to them, which the participants utilise and/or rework at a discursive level as well as a phenomenological level. (Davy, 2010, p. 107)

By presenting glimpses of life stories of trans ${ }^{\star}$ people, I illustrate the everyday navigation through the normative binary gender order from the perspective of people who do not (fully) fit this normative order.

\subsubsection{Reflections and Prospects}

In my article I have shown how imaginations of trans ${ }^{\star}$ lives as they are present in the knowledge of the culture of dominance are imaginable against the backdrop of medico-legal knowledge and the normatively binary gender order. This knowledge is not just present in medico-legal contexts, but also resonates in popular media coverage as well as in activist discourses. However, I have shown that trans` people are not simply victims of oppression, but rather actors inside these negotiations. Current 
imaginations of trans ${ }^{\star}$ people are embedded in long, often painful stories on disbelonging to certain gendered norms in the normative binary gender order. Following different sequences of current discourses on trans ${ }^{\star}$ gender, I have shown how the complex realities and ways of survival of trans* people are always entangled with various other aspects of their life-worlds. The realities of trans ${ }^{\star}$ people I outline as a puzzle with different pieces or a map with a different path. There is no single way of narrating and imagining trans* lives, but all different kinds of experiences are connected. They refer to each other, they deny each other, they connect to each other, they resist each other, they embrace each other. Taking a closer look on the current discourses concerning trans ${ }^{\star}$ issues in Germany, we can observe how deeply embedded they are in their intersections with questions of temporality and space, and thus of the discourse of gender in general. I have shown how, by taking up all these multilayered fragments, we acquire not only a deeper understanding of the complexity of gendered existences, but also repudiate the power system of knowledge and (in) visibility has on gender and its impact on trans ${ }^{\star}$ realities. It is not possible to go one step back, to erase the imperial status of the normative binary gender order. Yet it is possible to question its privileged status and its fame, by showing its complexities and reinterpretations. This complexity is hard to grasp in a linear text and a text only gives us a very small extract. My text should be read as an invitation for readers to seek out deeper insights of the complex negotiations of gendered (national) belonging and how gendered belonging and national interests are often negotiated against each other-most often without, or just with little, attention for the lived realities of gender-variant people themselves.

\section{References}

Aizura, A. Z., Cotton, T., Balzer, C./LaGata C., Ochoa, M., \& Vidal-Ortiz, S. (2014). Introduction. Transgender Studies Quarterly, 1(3), 308-319.

Aizura, A. Z. (2018). Mobile Subjects. Transnational Imaginaries of Gender Reassignment. Duke University Press.

APTN [Asia Pacific Transgender Network]. (2017, October 8). The "Gender Incongruence of Childhood" Diagnosis Revisited: A Statement From Clinicians And Researchers [Open letter]. Retrieved February 2, 2019, from http://www.weareaptn.org/2017/10/08/the-genderincongruence-of-childhood-diagnosis-revisited-a-statement-from-clinicians-and-researchers/

Arendt, H. (2006). Elemente und Ursprünge totalitärer Herrschaft [The Origins of Totalitarianism]. Piper.

Bundesgerichtshof. (2017, September 6). Beschluss - XII ZB 660/14 Frau-Zu-Mann- Transsexueller gilt rechtlich als Mutter eines von ihm geborenen Kindes. http://juris.bundesgerichtshof.de/ cgi-bin/rechtsprechung/document.py?Gericht=bgh\&Art=en\&sid=fe10ed417991e6e6c0d22991 9616930f\&anz $=1 \&$ pos $=0 \&$ nr $=79597$ \&linked $=$ pm\&Blank $=1$

Bundesverfassungsgericht. (2017, Oktober 10). Beschluss des Ersten Senats -1 BvR 2019/16 - Rn. (1-69). http://www.bverfg.de/e/rs20171010_1bvr201916.html

Butler, J. (1991). Das Unbehagen der Geschlechter [Gender Trouble]. Suhrkamp Verlag. 
Butler, J. (2010). Frames of War. When Is Life Grievable? Verso.

Çetin, Z., \& Prasad, N. (2015). Leerstellen im Diskurs um Frauenrechte ohne Rassismus und Klassismus. In Z. Çetin \& S. Taş (Eds.), Gespräche über Rassismus. Perspektiven \& Widerstände (pp. 107-116). Verlag Yılmaz-Günay.

Davy, Z. (2010) Transsexual Agents: Negotiating Authenticity and Embodiment within the UK's Medicolegal System. In: S. Hines and T. Sanger (Eds.), Transgender Identities: Towards a Social Analysis of Gender Diversity (pp. 106-126). Routledge.

Focus online regional. (2016, January 18). Angriff auf Frauen in Dortmund, Jugendliche wollten Transsexuellen-Paar steinigen: "Bin noch immer komplett fertig" [Attack on women. Adolecents wantet to stone a Transsexual couple to death: "I am still totally wasted"]. FOCUS online. Retrieved March 3, 2020, from https://www.focus.de/regional/dortmund/ angriff-auf-frauen-in-dortmund-jugendliche-wollten-transsexuellen-paar-steinigen-bin-nochimmer-komplett-fertig_id_5218233.html

Foucault, M. (1978). History and Sexuality. Pantheon Books.

Gesetzesentwurf der Bundesregierung. (2018). Entwurf eines Gesetzes zur Änderung der in das Geburtenregister einzutragenden Angaben. https://www.bmi.bund.de/SharedDocs/ downloads/DE/gesetzestexte/gesetzesentwuerfe/entwurf-aenderung-personenstandsgesetz. html

Haritaworn, J. (2012). Colorful Bodies in the Multikulti Metropolis. Vitality, Victimology and Transgressive Citizenship in Berlin. In T. T. Cotton (Ed.), Transgender Migrations. The Bodies, Borders, and Politics of Transition (pp. 11-31). Routledge.

Heerdegen, D., \& Höhne, M. S. (2018). On Normativity and Absence: Representation of LGBTI in Textbook Research. In A. Bock \& E. Fuchs (Eds.), Handbook of Textbook Studies (pp. 239-249). Palgrave Macmillan.

Hoenes, J. (2014). Nicht Frosch-Nicht Laborratte: Transmännlichkeiten im Bild. Eine kunstund kulturwissenschaftliche Analyse visueller Politiken [Not Frog-Not Laborartory Rat. Trans*masculinity in picture. An art- and cultural studies analysis of visual politics]. Transcript.

Höhne, M. (2017). Un_mögliches Passing? Das Nadelöhr der Norm [Im_possible Passing? The bottleneck of the Norm]. In I. Nagelschmidt, B. Borrego, D. Majewski \& L. König (Eds.), Geschlechtersemantiken und Passing be- und hinterfragen (pp. 21-40). Peter Lang.

Höhne, M. S., \& Klein, T. (2019). Disrupting Invisibility Fields-Provincializing 'Western Code' Trans* Narratives. Open Gender Journal. https://doi.org/10.17169/ogj.2019.24

Jung, C. (2016) Steinigung in Dortmund [stoning to death in Dortmund]. KOPP ONLINE. www.info. kopp-verlag.de/hintergruende/deutschland/christian-jung/steinigung-in-dortmund.html. Copy in possession of author.

Katholische Nachrichten. (2016, January 18). Dortmund: Nordafrikaner wollten Transsexuelle steinigen [Dortmund: North Africans wanted to stone transsexuals]. Katholische Nachrichten. Retrieved January 20, 2016, from http://www.kath.net/news/53639

LISTE mit empirischen MATERIAL Bundesvereinigung Trans*. (2018). Für geschlechtliche Selbstbestimmung und Vielfalt! https://www.bv-trans.de/

Lugones, M. (2008). Colonialidad y género. Tabula Rasa 9, 73-101.

Medizinischer Dienst des Spitzenverbandendes Bund der Krankenkassen e.V. [MDS]. (2009). Richtlinie des GKV-Spitzenverbandes zur Sicherung einer einheitlichen Begutachtung nach $\S 282$ Absatz 2, Satz 3 SGB V. Begutachtungsanleitung Geschlechtsangleichende Maßnahmen bei Transsexualität.

Mühlbauer, P. (2016, January 17). Dortmund: Nordafrikaner wollten angeblich Transsexuelle steinigen [Dortmund: Northafricans allegedly tried to stone Transsexuals to death]. Telepolis. www.heise.de/tp/druck/ob/artikel/47/47138/1.html

Nieder, T. O., Briken, P., \& Preuss, W. (2012). Schwerpunkte der Psychotherapie bei transsexuellen Entwicklungen. Der Neurologe und Psychiater, 13(10), 58-65. 
Noislamisation. (2016, January 16). Steinigung in Dortmund [Video]. YouTube. https://www.youtube. com/watch?v=3GoubXIRsvs

Ortmann, J. (2017, January 31). Eine Frage des Outens. Die ungewöhnliche Karriere von Oberstleutnant Anastasia, die als Soldat begann [The unusual career of Lieutenant Anastasia, who began as a soldier] (p. 29). Berlin Kurier. Copy in possession of author.

Oberstleutnant Anastasia aus Berlin und ihre Geschichte, die Mut macht. Frau Offizier war mal ein Mann [Lieutenant Anastasia from Berlin and her story that gives courage] (2017, January 1). (p. 1). Berlin Kurier. Copy in possession of author.

Prosser, J. (1998). Second Skins. The Body Narratives of Transsexuality. Columbia University Press. Puar, J. K. (2007). Terrorist Assemblages: Homonationalism in Queer Times. Duke University Press.

Puar, J. K. (2013). Rethinking Homonationalism. International Journal of Middle East Studies, 45(2), 336-339. https://doi.org/10.1017/S002074381300007X

Reporter. (2018, March 21). Transgender: Pattis geschlechtsangleichende Operation [Video]. YouTube. https://www.youtube.com/watch?v=ZnGdC4f_77E

Rommelspacher, B. (1998). Dominanzkultur. Texte zu Fremdheit und Macht. Orlando Frauenverlag.

Schaffer, J. (2008). Ambivalenzen der Sichtbarkeit. Über die visuellen Strukturen der Anerkennung. Transcript.

Transsexworks. (n.d.). Bedarfserhebung. Retrieved March, 2019, from http://transsexworks. com/?page_id=170\&lang=de_DE

Vertovec, S. (2009). Transnationalism. Routledge.

Wegener, A., \& Engelberg, M. (2016, January 16). Transsexuelle in Dortmund von drei Männern angegriffen-jetzt sprechen die Opfer: "Wir sollten auf offener Straße gesteinigt werden" [Transsexuals attacked in Dortmund by three men-now the victims are talking: "We were supposed to be stoned to death at the street"]. Bild-Zeitung online. Retrieved January 20, 2016, from https://www.bild.de/regional/ruhrgebiet/toetungsdelikt-steinigung/wir-sollten-aufoffener-strasse-gesteinigt-werden-44171194.bild.html\#fromWall

World Health Organisation [WHO]. (2016). Classifications of Mental and Behavioural Disorder: Clinical Descriptions and Diagnostic Guidelines. International Classification of Diseases (ICD-10, 10th revision). Retrieved from https://www.icd10data.com/ICD10CM/Codes/F01-F99/ F60-F69/F64- 